\title{
STUDIES ON THE PECTIC POLYSACCARIDES OF WATTAKKA CULTIVAR (Cucurbita spp.) AND SOME APPLICATIONS IN FOOD FORMULATIONS
}

\author{
By \\ Herath Mudiyanselage Theja Herath
}

Thesis submitted to the University of Sri Jayewardenepura for the award of the degree Master of Philosophy in Chemistry on Studies on the pectic polysaccharides of Wattakka Cultivar (Cucurbita spp.) and some applications in food formulations.

May 2004 
The work described in this thesis was carried out by me under the supervision of Dr. Jaanaki Gooneratne and Prof. A.M. Abeysekera and a report on this thesis has not been submitted to any University for another degree.

\section{Hutterath .....}

H. M. Theja Herath 
We certify that above statement made by candidate is true and that this thesis is suitable for submission to the university for the purpose of evaluation.
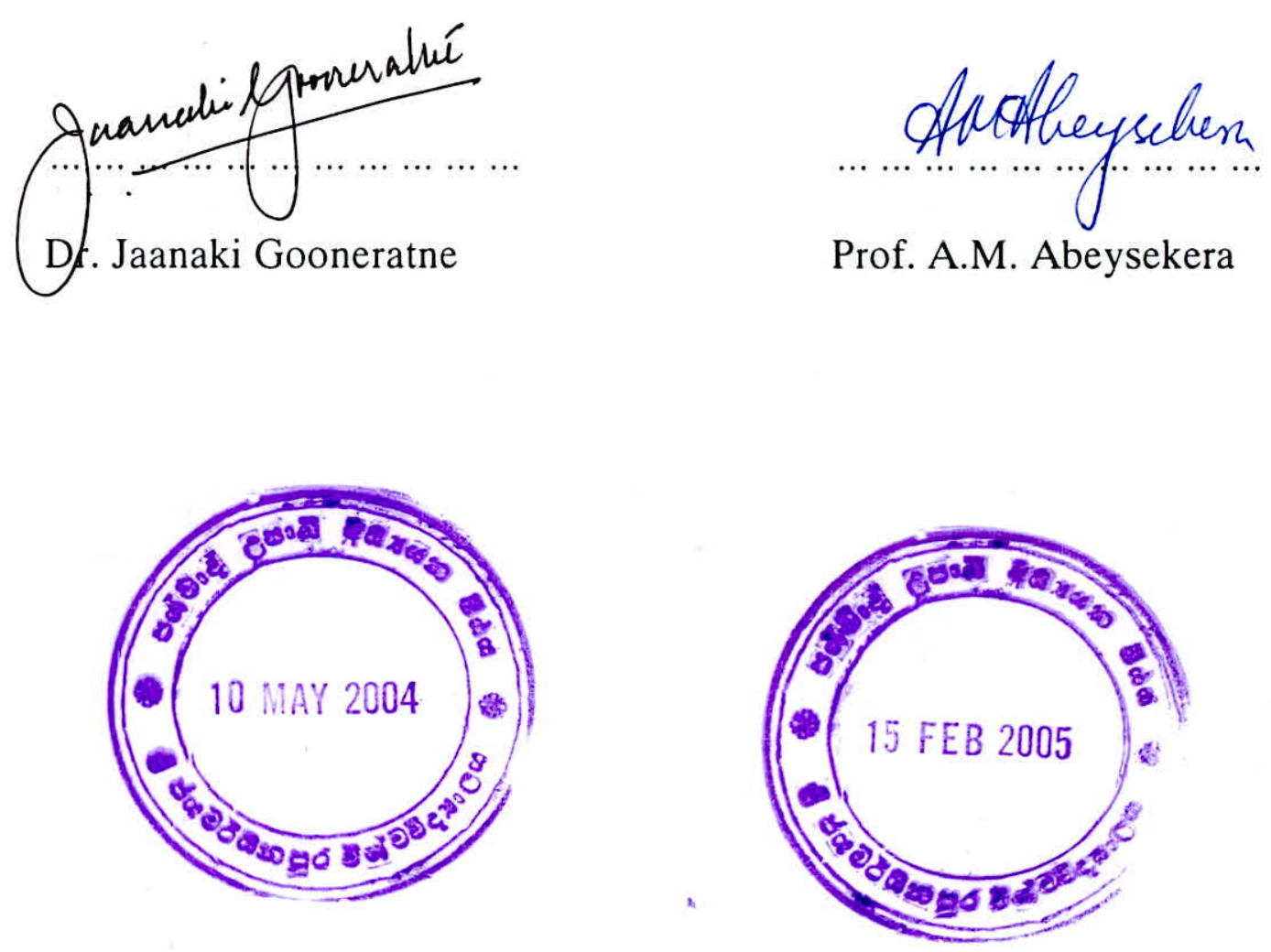
Dedicated

To

My loving parents, husband, son Hansaka

and

daughter Amanda. 


\section{TABLE OF CONTENTS}

Page No

LIST OF TABLES

LIST OF FIGURES vi

ABBREVIATIONS viii

ACKNOWLEDGEMENTS $\quad \mathrm{x}$

ABSTRACT Xii

$\begin{array}{lll}1.0 & \text { INTRODUCTION } & 01\end{array}$

$\begin{array}{lll}\text { 1.1 Background to the present study } & 01\end{array}$

$\begin{array}{lll}1.2 & \text { Pectic polysaccharides } & 03\end{array}$

$\begin{array}{ll}\text { 1.2.1 Pectins as cell wall component } & 03\end{array}$

$\begin{array}{ll}\text { 1.2.2 Occurrence of pectins in plants } & 06\end{array}$

$\begin{array}{ll}\text { 1.2.3 Structure of pectic polysaccharides } & 08\end{array}$

$\begin{array}{ll}\text { 1.2.3.1 Rhamnogalacturonans } & 09\end{array}$

$\begin{array}{ll}\text { 1.2.3.2 Neutral pectic polysaccharides } & 09\end{array}$

$\begin{array}{ll}\text { 1.2.4 Physical properties of pectins } & 12\end{array}$

$\begin{array}{ll}\text { 1.2.5 Chemical properties of pectins } & 14\end{array}$

$\begin{array}{ll}\text { 1.2.6 Manufacturing processes of pectins } & 15\end{array}$

$\begin{array}{lll}1.3 & \text { Food applications of pectin } & 19\end{array}$

$\begin{array}{ll}\text { 1.3.1 Pectins in the food industry } & 19\end{array}$

$\begin{array}{ll}\text { 1.3.1.1 Gelling properties } & 20\end{array}$

$\begin{array}{ll}\text { 1.3.1.2 } \text { Body agent / Viscofiers } & 24\end{array}$ 
1.3.1.3 Emulsifiers

1.3.1.4 Fat replacers

1.3.1.5 Stabilizer in the milk system

1.3.1.6 Functional food ingredient

\subsection{MATERIALS AND METHODS}

2.1 Materials

2.1.1 Fruits of Cucurbita spp.

2.1.2 Chemicals and enzymes

\subsection{Methods}

2.1.2 Isolation and characterization of pectic material

2.2.1.1 Preparation of Alcohol Insoluble Residue (AIR)

2.2.1.2 Sequential extraction of cell wall polymers

2.2.1.3 Determination of monomer sugar composition

2.2.1.4 Anion-Exchange Chromatography

2.2.2 Determination of non-starch polysaccharides of Cucurbita spp.

2.2.3 Isolation and characterization of pectin from Cucurbita spp. for food applications

2.2.3.1 Processing of raw material

2.2.4 Extraction of pectin

2.2.5 Chemical characterization of pectins

2.2.5.1 Determination of methoxyl content

2.2.5.2 Determination of acetyl content

2.2.5.3 Determination of degree of esterification 
2.2.6 Physical characteristics of pectin

2.2.6.1 Determination of average molecular weight by Intrinsic Viscosity Method

2.6.6.2 Determination of viscosity at different $\mathrm{pH}$ by using Citric-Phosphate buffer

2.2.7 Food applications of pectins

2.2.7.1 Wattakka pectin as a gelling agent

2.2.7.2 Wattakka pectin as a body and texture agent in dietetic fruit juice

2.2.7.3 Wattakka pectin as a stabilizer in stirred yogurt

2.2.7.4 Emulsion stability of Wattakka pectin

2.3 Samples and data analysis

\subsection{RESULTS AND DISCUSSION}

3.1 Chemistry of cell wall polysaccharides of Cucurbita spp.

3.1.1 Isolation and characterization of pectic polysaccharides of Wattakka ( Cucurbita spp.)

3.1.2 Non-starch polysaccharides of Cucurbita spp.

3.2.1 Extraction of pectic material

3.2.2 Effect of pre-processing on extraction of pectic material from the three cultivars of Cucurbita spp.

3.2.3 Application of Wattakka pectin as a gelling agent 
3.2.5 Application of Wattakka pectin as a stabilizer in stirred yogurt

3.2.6 Application of Wattakka pectin as a emulsion stabilizer

4.0 CONCLUSIONS

82

5.0 REFERENCES

84

6.0 LIST OF PUBLICATIONS AND COMMUNICATIONS

98

FROM THESIS 


\section{LIST OF TABLES}

Table 1.1 Cell wall polysaccharides composition of parenchymatous and lignified tissues of edible plant organs

Table 1.2 Approximate pectin content of various plant materials

Table 3.1 Sugar composition of extracts of cell wall material of after sequential extraction

Table 3.2 Monomer sugar composition of CDTA-soluble and $\mathrm{Na}_{2} \mathrm{CO}_{3}$-soluble fractions of Wattakka after anion exchange chromatography.

Table 3.3 Monomer sugar composition of non-starch polysaccharides

( as dietary fibre) of Wattakka, Meemini and Butternut

Table 3.4 Sugar composition of pectic material extracted from Wattakka,

Meemini and Butternut cultivars of Cucurbita spp using industrial extraction procedures

Table 3.5 Chemical characteristics of pectin extracted from Wattakka, Meemini and Butternut using industrial extraction procedures 64

Table 3.6 Gelling characteristics of pectin of Wattakka 


\section{LIST OF FIGURES}

Figure 1.1 The structural model of primary cell wall of dicots

Figure 1.2 Diagrammatic representation of some structural features of pectins from the (A) Middle lamellae and (B) Primary cellwalls 10

$\begin{array}{lll}\text { Figure } & 1.3 \quad \text { Manufacturing process of pectin } & 16\end{array}$

$\begin{array}{lll}\text { Figure 2.1 Photographs of Cucurbita spp. } & 30\end{array}$

Figure 3.1 Elution profiles of CDTA and $\mathrm{Na}_{2} \mathrm{CO}_{3}$ fractions of cell wall material of Wattakka from anion exchange chromatography $\quad 55$

Figure 3.2 Determination of the molecular weight of Wattakka pectin 66

Figure 3.3(a) Viscosity of Wattakka pectin at different pH 67

Figure 3.3(b) Viscosity of Citrus pectin at different pH 68

Figure 3.4(a) Specific viscosity of Wattakka pectin at different $\mathrm{pH} \quad 70$

Figure 3.4(d) Specific viscosity of Citrus pectin at different pH

Figure 3.5 Effect of varying concentration of Wattakka pectin on the viscosity of dietetic fruit juice

Figure 3.6 Effect of varying concentration of Wattakka pectin on turbidity of dietetic fruit juice

Figure 3.7 $\mathrm{pH}$ of stirred yogurts with increasing concentration of Wattakka pectin when used as a stabilizer 
Figure 3.8 Viscosity of stirred yogurts with increasing concentration of Wattakka pectin when used as stabilizer

Figure 3.9 Effect of varying concentration of Wattakka pectin on the stabilizing rate of oil water emulsion. 


\begin{tabular}{|c|c|}
\hline & ABBREVIATIONS \\
\hline$\eta$ & Viscosity of solution \\
\hline$\eta_{1}$ & Intrinsic Viscosity \\
\hline$\eta_{\mathrm{s}}$ & Viscosity of solvent \\
\hline$\eta_{\mathrm{sp}}$ & Specific Viscosity \\
\hline $\mathrm{AEC}$ & Anion Exchange Chromatography \\
\hline AIR & Alcohol Insoluble Residue \\
\hline Ara & Arabinose \\
\hline CDTA & Cyclo-Hexane-trans-1-2-diamine-NNN'N' tetra acetate \\
\hline $\mathrm{DF}$ & Dietary Fibre \\
\hline DMSO & Di- Methyl Sulphur Oxide \\
\hline $\mathrm{EC}$ & Emulsifying Capacity \\
\hline EDTA & Ethylene Diamine Tetra Acetate \\
\hline ES & Emulsifying Stability \\
\hline F/C Yogurt & Full Cream Yogurt \\
\hline FAU & Formazine Attenuation Unit \\
\hline Gal & Galactose \\
\hline $\mathrm{GC}$ & Gas Chromatograph \\
\hline Glu & Glucose \\
\hline $\mathrm{HM}$ & High Methoxyl \\
\hline Kcal & kilo calorie \\
\hline $\mathrm{KPa}$ & Kilo pascal \\
\hline
\end{tabular}


LM Low Methoxyl

Man Mannose

N Newton

N/F Yogurt Non Fat Yogurt

NSP Non Starch Polysaccharides

SD Standard Deviation

SDS Sodium Dodecyl Sulphate

SR Stabilizing Rate

UA Uronic acid

Xyl Xylose 


\section{ACKNOWLEDGEMENT}

I wish to express my most sincere appreciation and gratitude to my supervisor, $\mathrm{Dr}$ Jaanaki Gooneratne, Senior Research Officer, Industrial Technology Institute, for the generous advice and guidance given, in conducting this investigation. Her unhesitant help and co-operation at all times has contributed immensely to make this study a success. It is my bounden duty to thank her most sincerely.

I especially, wish to express my deepest sense of gratitude to my supervisor, Prof. A. M. Abeysekera, Dean, Faculty of Applied Sciences, Professor of Chemistry, University of Sri Jayewardenepura, for his valuable advice, kind guidance and professional expertise throughout my study.

My deep sense of gratitude is expressed to Dr. Nanadani Ediriweera, Head, Agro and Food Technology Division, and Dr. A. M. Mubarak, Director, Industrial Technology Institute, for granting me the opportunity to carry out this study.

I extend my gratitude to National Science Foundation (NSF) for providing financial assistance to carryout my work successfully.

I wish to acknowledge the help of the staff, Dept. of Taxonomy, Plant Genetic Resources Centre (PGRC), Gannoruwa, for identification of cultivars and their assistance. 
I wish to thank my colleagues for their kind help in various ways and their friendly cooperation. Especially Ms. Siryani Kumari for her kind support given during my laboratory work.

I extend my thanks to Ms. Chamari Hettiarachchi and Mr. M.Yoheshwaran for their fullest support during finalizing of the thesis. I extend my thanks to Mr. T. Wimalasena, Laboratory Assistant for his kind help in various ways.

I wish to thank Mr. K.S. Wijenayake, Technical Officer, Dept of Zoology, University of Sri Jayewardenepura, for photographing of raw materials and Mr. Rangoda, Technical Officer for his kind help in many ways.

Last but not the least, I am extremely grateful to my husband Gamini and son, Hansaka and daughter, Amanda for their patience and support during the progress of this work 
Studies on the pectic polysaccharides of Wattakka cultivar (Curcubita spp.) and its applications in food formulations.

\section{H.M.T Herath.}

\section{ABSTRACT}

In this study, pectin from the fruits of Cucurbita spp., namely, Wattakka, Meemini and Butternut cultivars, was investigated as a potential source for use in food industry. Towards this end, basic and applied research on the following work was carried out. (a) Isolation and characterization of the cell wall polysaccharides of Cucurbita moschata, Watakka cultivar, using non- degradative methods. The native pectin was purified and characterized to obtain its monomer sugar composition. (b) A comparison was also made on the non-starch polysaccharide compositions of the three cultivars of Cucurbita spp. as components of dietary fibre. (c) Extraction of pectin from the three cultivars of Cucurbita spp. using an industrial process and determination of chemical and physical characteristics and (d) a study of the applications of pectin from the Wattakka cultivar in some food formulations.

The pectic polysaccharides of the cell walls of Wattakka were isolated as alcohol insoluble residue using a modified method described by $\mathrm{Ng}$ et al. (1998). This alcohol insoluble residue, was sequentially extracted, under non- degradative methods, using CDTA (0.05 M, pH 6.5) at $20^{\circ}-22{ }^{\circ} \mathrm{C}$, for $6 \mathrm{~h}$ (CDTA-1) and $2 \mathrm{~h}$ (CDTA-2), respectively. The residue thus obtained was further extracted with $\mathrm{Na}_{2} \mathrm{CO}_{3}(0.05 \mathrm{M})$ at $8^{\circ} \mathrm{C}$, for $24 \mathrm{~h}\left(\mathrm{Na}_{2} \mathrm{CO}_{3}-1\right)$ and at $20^{\circ}-22{ }^{\circ} \mathrm{C}$ for $2 \mathrm{~h}\left(\mathrm{Na}_{2} \mathrm{CO}_{3}-2\right)$, respectively. The extracts of all fractions were filtered, neutralised and dialysed exhaustively and freeze- 
dried. The monomer sugar compositions of the fractions were determined after $12 \mathrm{M}$ $\mathrm{H}_{2} \mathrm{SO}_{4}$ hydrolysis, neutralization and derivatization to alditol acetates and quantified by GC techniques. The uronic acid content was determined calorimetrically.

The yield of the cell wall material of the edible portion of the Wattakka fruit was $29.6 \%$, (as alcohol insoluble material), consisting of $91 \%$ of carbohydrates, mainly pectic polysaccharides. The total CDTA and $\mathrm{Na}_{2} \mathrm{CO}_{3}$ fractions accounted for $24.7 \%$ and $3.7 \%$ respectively, of the original material. The monomer sugar composition of the fractions, showed that the branching points of pectic material (as indicated by the ratio of rhamnose; uronic acid) were high in CDTA-1 (1:38) and CDTA-2 fractions (1:30), while the $\mathrm{Na}_{2} \mathrm{CO}_{3}-1$ (1:22) and $\mathrm{Na}_{2} \mathrm{CO}_{3}-2$ (1:25) fractions contained less branching points. The major neutral sugar in all fractions was galactose, which was a significant characteristic of Cucurbita spp.

The main fraction of the cell wall CDTA-1, was subjected to anion exchange chromatography (DEAE- Trisacryl column), more or less a homogenous individual polymer was obtained, when eluted with $0.25 \mathrm{M} \mathrm{NaCl}$. This polymer contained $84 \%$ of uronic acid, with a rhamnose to uronic acid ratio of 1: 44 . The major neutral sugar of the polymer was galactose, with substantial amounts of arabinose and mannose.

The non-starch polysaccharides (NSP) of all three cultivars were determined as dietary fibre. Wattakka contained $11.8 \mathrm{~g} / 100 \mathrm{~g}$ of NSP, of which $22 \%$ was soluble fibre. The NSP of the other two cultivars was less, Meemini containing $9.1 \mathrm{~g} / 100 \mathrm{~g}$ (20\% soluble 
fibre) and Butternut containing $8.9 \mathrm{~g} / 100 \mathrm{~g}$ (18\% soluble fibre). NSP of Cucurbita spp. may be of importance in terms of its physiological role in human systems.

The pectin from all three cultivars of Cucurbita spp. was extracted under industrial conditions (in $\mathrm{HCl}$ at $\mathrm{pH} 1.3$ for $2 \mathrm{~h}$, followed by alcohol precipitation), after preprocessing using three different methods. The yields of the pectin were in the range of 7.4 to $28.8 \%$ for all three cultivars and was found to be dependent on the method of pre-processing. These yields are in the same range of values reported for citrus $(25 \%)$ and apple ( $15-18 \%)$.

The chemical characterization of the industrially extracted Watakka pectin was classified as a high methoxyl (HM) pectin, as it had methoxyl content of over $7 \%$. However, the Wattakka pectin showed weak gelling properties (gel grade 100) as compared to citrus pectin (gel grade 150$)$, with a low rupture point $(0.7 \mathrm{~K} \mathrm{~Pa})$ and a low compression ability $(18 \mathrm{~N})$. The presence of higher concentrations of neutral sugars in the pectic polymer may hinder the gel forming ability. Both other cultivars, Meemini and Butternut, did not demonstrate gel forming characteristics, probably due the high acetyl content (over $2 \%$ ). Hence it could be concluded that the use of these two cultivars in food applications are limited.

Wattakka pectin had an average molecular weight of 2927 daltons and its viscosity properties increasing markedly at a pH of 4.6 at a concentration of $1 \%(\mathrm{w} / \mathrm{v})$. 
Wattakka pectin was applied to several food formulations and its technological characteristics were investigated as compared to that of citrus pectin.

Wattakka pectin was incorporated into a dietetic fruit juice, showed a higher viscosity values (18-30 cP) as compared to citrus pectin (12-17 cP), at concentrations of 0.15 $0.25 \%(\mathrm{w} / \mathrm{v})$, imparting a body and texture to the product.

Wattakka pectin when added to a formulation of stirred yoghurt (non-fat), demonstrated the formation of a stabilized milk-pectin complex by showing an increase in the viscosity, ranging from 2200 to $3800 \mathrm{cP}$, at $\mathrm{pH} 4-4.5$ and at concentrations ranging from $0.15-0.25 \%(\mathrm{w} / \mathrm{v})$. These stabilizing properties, however, were not demonstrated when Wattakka pectin was used in fat containing stirred yoghurt formulations.

When Wattakka pectin was used in emulsions of oil-in-pectin solutions, an emulsion stability of $100 \%$ was obtained at a concentration of $2 \%(\mathrm{w} / \mathrm{v})$, as compared to citrus pectin which showed a $40 \%$ stability, under similar conditions. 